\title{
Maximal oxygen uptake in trained and untrained 15-year-old boys
}

\author{
Z. Nikolić and N. Ilić \\ Faculty of Physical Education, University of Belgrade, Yugoslavia
}

\begin{abstract}
The purpose of this study was to assess maximal aerobic power $\left(\mathrm{VO}_{2 \max }\right)$ in trained and untrained 15-year-old boys. The trained subjects (18) were junior swimmers from a Belgrade swimming team, and the untrained ones (12) were from a Belgrade high school. $\dot{V}_{\mathrm{O}_{2} \max }$ was directly measured during progressive cycle ergometer exercise using open circuit spirometry. No significant differences in height, mass, percentage fat and vital capacity were noted between the trained and untrained groups. Maximal aerobic power (overall, relative and in relation to lean body mass) in absolute values, and expressed per kilogram of body mass and lean body mass, was $31.5 \%$, $21.2 \%$ and $20.6 \%$, respectively, higher in the trained than in the untrained group $(P<0.05)$. These data suggest that physical training significantly increases maximal aerobic power in young subjects.
\end{abstract}

Keywords: $\dot{V}_{\mathrm{O}_{2 \max }}$ lean body mass, children, training

Maximal oxygen uptake $\left(\dot{V}_{\mathrm{O}_{2 \max }}\right)$ is generally accepted as a measure of cardiorespiratory fitness. It is an integrated measurement of the state of the oxygen transport system, and includes the functions of the pulmonary, cardiovascular and muscular systems.

Various investigators have found that $\dot{V}_{\mathrm{O}_{2} \max }$ increases during the growth period in children ${ }^{1-3}$. Several studies have been undertaken to evaluate the training influences on $\dot{V O}_{2 \text { max }}$ in children of various ages $^{4-7}$.

To evaluate the influence of physical training one must distinguish the maturation-influenced changes from those that were the product of physical training. Cross-sectional studies comparing $\mathrm{VO}_{2}$ max changes in trained and/or untrained children from 10 to 16 years of age $e^{8-12}$, all agree that one should distinguish between the training and peak height growth velocity influences on $\dot{V}_{\mathrm{O}_{2} \text { max }}$ changes during the maturation period.

Since there are few data concerning cardiorespiratory function of Yugoslav children, the purpose of this study was to compare $\dot{V}_{\mathrm{O}_{2}}$ max in well trained and untrained boys of similar age.

Address for correspondence: Zlatomir Nikolić, Faculty of Physical Education, 11030 Belgrade, Blagoja Parovića 156, Yugoslavia (C) 1992 Butterworth-Heinemann Ltd 0306-3674/92/010036-03

\section{Materials and methods}

Twelve untrained 15-year-old boys and 18 welltrained junior swimmers (mean age 14.7 years) participated in this study. The subjects from both experimental groups received full explanations of the procedure. Before the investigation, the subjects and their parents gave written consent for the study. The study was approved by the Research Ethics Committee of the University of Belgrade.

The anthropometric variables measured were height, mass, skin fold thickness on the left side and vital capacity (VC), converted to body temperature, ambient barometric pressure, saturated with water vapour (BTPS) measured in standing position using a Godart expirograph (Godhart, Bilthoven, Holland). The body fat percentage and lean body mass were estimated by the formula proposed by Parizkova ${ }^{13}$.

The ergometry tests were performed on a cycle ergometer (Monark, W. Wilken, Physikalisch Mediz. Gezäte, Berlin, Germany) at 60 r.p.m. The work rate was increased by $30 \mathrm{~W}$ every $3 \mathrm{~min}$ until the subjects reached exhaustion (i.e. when the subject was unable or unwilling to continue despite strong verbal encouragement from the experimenters). Expired gases were collected in Douglas bags in the second half of the third minute of each exercise bout. Minute ventilation was measured with a Siebe-Gorman gas meter (Siebe-Gorman, London, UK). The fractional concentration of oxygen and carbon dioxide in expired air was determined with Beckman OM11 and LB2 analysers (Beckman Instruments, Illinois, USA), respectively, which were calibrated before the analysis with gases of known oxygen and carbon dioxide concentrations. Heart rate was monitored during the last $15 \mathrm{~s}$ of each work bout by electrocardiograph. All tests were performed in the morning after a light breakfast.

Oxygen uptake was considered to be maximal if the increase between the two successive work rates was not greater than $10 \%$ (levelling-off criterion) and a maximal heart rate was within 10 beats/min of the age-predicted maximal values.

Descriptive data are presented as mean(s.d.). The unpaired $t$ test was used to determine significance of changes between sample groups. Pearson product moment correlations were used to determine the relationship between various anthropometric variables and $\mathrm{VO}_{2 \text { max }}$. 
Table 1. Anthropometric values of trained and untrained boys

\begin{tabular}{lcc}
\hline & $\begin{array}{c}\text { Untrained } \\
(\mathrm{n}=12)\end{array}$ & $\begin{array}{c}\text { Trained } \\
(\mathrm{n}=18)\end{array}$ \\
\hline Height $(\mathrm{cm})$ & $168.04(5.9)$ & $170.78(7.3)$ \\
Mass $(\mathrm{kg})$ & $54.05(5.5)$ & $59.99(9.0)$ \\
Percentage body fat & $13.94(4.5)$ & $15.06(3.05)$ \\
Vital capacity (I $\mathrm{BTPS})$ & $4.09(0.36)$ & $4.57(0.87)$ \\
\hline
\end{tabular}

Values are mean(s.d.)

Table 2. Maximal aerobic power of trained and untrained boys

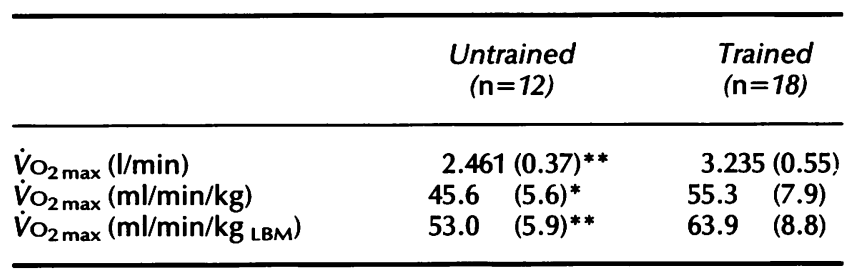

Values are mean(s.d.) $\left(^{*} P<0.02,{ }^{* *} P<0.001\right.$; significantly different from trained group

LBM, lean body mass

\section{Results}

Physical characteristics of subjects are given in Table 1. Maximal aerobic power values are given in Table 2.

Trained subjects did not differ significantly in anthropometric values. Maximal aerobic power (overall, relative and in relation to lean body mass) was significantly higher in swimmers than in untrained boys. Overall $\mathrm{VO}_{2 \max }$ in the trained group was $31.5 \%$ greater than in the untrained subjects. When expressed per $\mathrm{kg}$ body mass and lean body mass, it was 21.2 and $20.6 \%$ greater in the trained subjects.

Correlations between $\dot{V}_{2}$ max and some anthropometric variables for both subject groups are given in Table 3. All presented correlations are positive and statistically significant in the trained group, while in the untrained group statistically significant correlations are found between lean body mass and $\dot{V}_{\mathrm{O}_{2} \max }$ $\left(1 \min ^{-1}\right)$, and between body height and VC.

\section{Discussion}

Maximal oxygen uptake can be expressed in litres per minute or in relation to body mass. Selection of subjects has much to do with the results of such studies. It is always questionable whether the selected group is representative of the population.

The trained subjects were chosen from a Belgrade swimming team after 2 years of systematic training, while the untrained boys were taken randomly from several classes of a Belgrade high school.

Contrary to our expectations, there were no differences in height, mass, VC or percentage body fat between the two groups. The swimmers had a slightly higher fat percentage than the untrained boys. This could be the effect of adaptation to long hours spent in water, which is a good heat conductor, such that the swimmers are better isolated from excessive heat loss in water. The difference in VC between the two groups was 0.481 , which was not statistically significant. This is strange, as a relatively short training period significantly increases VC in swimmers ${ }^{14}$. These findings could mean that the subject groups were at a similar developmental level concerning body dimensions.

Comparing anthropometric results (body height, mass and percentage body fat) in this study with the data of other investigators, some authors give significantly higher values than are presented in this study $1,3,15$ but the anthropometric dimensions of our subjects were similar to those presented by others $^{5,7,9,12,16}$

Maximal oxygen uptake values in untrained boys are similar to the data given by other investigators for the same age group ${ }^{3,8,16}$, but some other authors obtained significantly higher $\dot{V}_{\mathrm{O}_{2} \text { max }}$ per kilogram body mass values in untrained boys than are given here $1,10,11$.

There could be many reasons for the higher $\dot{V}_{\mathrm{O}_{2}}$ values in untrained subjects in these studies: they could participate in vigorous physical activity in free time as well as during regular physical education classes in school; they were better endowed for high $\dot{V}_{\mathrm{O}_{2} \text { max }}$ values; the method employed in determination of $\dot{V}_{\mathrm{O}_{2} \max }$. All three studies used treadmill running as a mode of exercise: it is well known that treadmill running elicits higher $\dot{V}_{\mathrm{O}_{2}}$ max values than does the cycle ergometer exercise ${ }^{17}$.

Table 3. Correlations between some anthropometric variables and $\dot{V}_{\mathrm{O}_{2, \max }}$ values

\begin{tabular}{|c|c|c|c|c|c|c|c|c|c|c|c|c|}
\hline \multirow[t]{2}{*}{ Variable } & \multicolumn{6}{|c|}{ Trained group } & \multicolumn{6}{|c|}{ Untrained group } \\
\hline & 2 & 3 & 4 & 5 & 6 & 7 & 2 & 3 & 4 & 5 & 6 & 7 \\
\hline $\begin{array}{l}\text { Height } \\
\text { Mass } \\
\text { LBM } \\
\text { VC } \\
\dot{V} \mathrm{O}_{2 \max } \\
\dot{V} \mathrm{O}_{2 \max } / \mathrm{kg} \\
\dot{V} \mathrm{O}_{2 \max } /(\mathrm{LBM})\end{array}$ & $\begin{array}{l}0.88 \\
-\end{array}$ & $\begin{array}{l}0.91 \\
0.97\end{array}$ & $\begin{array}{l}0.83 \\
0.82 \\
0.85 \\
-\end{array}$ & $\begin{array}{l}0.63 \\
0.59 \\
0.62 \\
- \\
-\end{array}$ & $\begin{array}{l}\overline{0} \\
- \\
\overline{-} \\
\overline{-} \\
-\end{array}$ & $\begin{array}{l}- \\
- \\
- \\
\overline{0} \\
0.5 \\
0.95 \\
-\end{array}$ & $\begin{array}{l}0.71 \\
-\end{array}$ & $\begin{array}{l}0.85 \\
0.85 \\
-\end{array}$ & $\begin{array}{l}0.74 \\
0.59 \\
0.75 \\
-\end{array}$ & $\begin{array}{l}\overline{-} \\
\overline{0} .62 \\
\overline{-}\end{array}$ & $\begin{array}{l}- \\
\overline{-} \\
\overline{0} \\
0.73 \\
-\end{array}$ & $\begin{array}{l}- \\
- \\
- \\
\overline{0} \\
0.79 \\
0.91 \\
-\end{array}$ \\
\hline
\end{tabular}

All correlations are significant at the $P=0.05$ level

LBM, lean body mass 
$\dot{V}_{\mathrm{O}_{2 \max }}$ in absolute and relative terms was significantly higher in the trained than in the untrained group. This could be expected, as swimming is an aerobic exercise which greatly taxes the oxygen transport system. This kind of training augments peak oxygen uptake and therefore increases physical fitness $4,5,9,18$.

Absolute $\dot{\mathrm{V}}_{2 \max }$ values were $31.5 \%$ higher and the relative values (per kilogram of body mass and lean body mass) were approximately $20 \%$ greater in the trained group, which was significant. Smaller relative differences were produced because the body mass and fat percentage were not similar in the groups studied. In this way, when the aerobic power is expressed per mass unit, the real differences are emphasized. Therefore, we can obtain a better measure of active protoplasmic mass which contracts the required oxygen uptake ${ }^{1,17}$

Maximal aerobic power $(1 / \mathrm{min})$ in trained boys was similar to the data presented by other investigators who examined $\dot{V} \mathrm{O}_{2 \text { max }}$ in trained boys of the same age group ${ }^{5,6,9,18}$. Relative $\dot{V}_{\mathrm{O}_{2} \max }$ values in swimmers are similar to those obtained by the abovementioned investigators ${ }^{6,18}$, but significantly lower than those reported by some other studies ${ }^{7,9}$, which were about $23 \%$ higher. This could be caused by better training of the examined groups. Our subjects trained for 2 years before the study, swimming $3-5 \mathrm{~km}$ daily six times per week, while the ones in the Paterson group 6 trained intensively for 5 years. The other reason could be, as mentioned before, the type

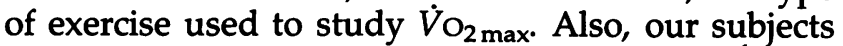
were more massive than in the Paterson ${ }^{6}$ and Sprynarova ${ }^{7}$ groups. As these authors do not give any data on lean body mass, we cannot compare $\dot{V}_{\mathrm{O}_{2} \max }$ values in relation to it.

The importance of quantity of physical training is shown in a recently published paper ${ }^{5}$. The group that performed twice as much swimming exercise attained significantly higher relative $\dot{V}_{\mathrm{O}_{2}}$ max values. Comparing their data (absolute and relative) with the results of our trained subjects, we could say that the swimmers in the present study were similarly trained to the well trained ones in their study ${ }^{5}$.

Several investigators found high correlation between $\dot{V}_{\mathrm{O}_{2} \max }$ and body mass and height ${ }^{1,6,10,11,15}$. In this study significant correlation between $\dot{V}_{\mathrm{O}_{2}}$ max and body mass or height were obtained in the swimmers group ( $r=0.59$ and 0.626 , respectively) as well as between $\dot{V}_{\mathrm{O}_{2}}$ max and lean body mass $(r=$ 0.617 ). In the untrained group there was a significant correlation between lean body mass and $\dot{V}_{\mathrm{O}_{2} \max }$ suggesting that the greater the active protoplasmic mass, the greater the maximal aerobic power.

As the subjects were of the same age, it could be concluded that the differences in maximal aerobic power between groups were the result of selfselection of highly successful individuals. The genetic predisposition towards success in athletic activities may account for the maximal oxygen uptake difference between the trained and untrained groups, rather than the influence of training.

\section{References}

1. Astrand P-O. Experimental Studies of Physical Working Capacity in Relation to Sex and Age. Copenhagen: Ejnar Munksgaard, 1952.

2 Sunnegardh J, Bratteby L-E. Maximal oxygen uptake, anthropometry and physical activity in a randomly selected sample of 8 and 13 year old children. Eur J Appl Physiol 1987; 56: 266-72.

3 Vanden Eynde B, Vienne D, Vuylsteke-Wauters M, Van Gerven D. Aerobic power and pubertal peak height velocity in Belgian boys. Eur J Appl Physiol 1988; 57: 430-4.

4 Astrand P-O, Eriksson BO, Nylander J et al. Girl swimmers. Acta Paediatr 1963; 147 (Suppl).

5 Mercier J, Vago P, Ramonatxo M, Bauer C, Prefaut C. Effect of aerobic training quantity on the $\dot{V}_{\mathrm{O}_{2}}$ max of circumpubertal swimmers. Int J Sports Med 1987; 8: 26-30.

6 Paterson DH, McLellan TM, Stella RS, Cunningham DA. Longitudinal study of ventilation threshold and maximal $\mathrm{O}_{2}$ uptake in athletic boys. J Appl Physiol 1987; 62: 2051-7.

7 Sprynarova $S$. The influence of training on physical and functional growth before, during and after puberty. Eur J Appl Physiol 1987; 56: 719-24.

8 Cunningham DA, Patterson DH, Blimkie JR, Donner AP. Development of cardiorespiratory function in circumpubertal boys. J Appl Physiol 1984; 56: 302-7.

9 Francaux M, Ramyead R, Sturbois X. Physical fitness of young Belgian swimmers. J Sports Med 1987; 27: 197-204.

10 Kemper HCG, Verschuur R. Maximal aerobic power. Med Sports Sci 1985; 20: 107-26.

11 Kemper HCG, Verschuur R. Longitudinal study of maximal aerobic power in teenagers. Ann Hum Biol 1987; 14: 435-44.

12 Sobolova V, Seliger V, Grusova D et al. The influence of age and sports training in swimming on physical fitness. Acta Paediatr Scand 1971; 217 (Suppl): 63-7.

13 Parizkova J. Total body fat and skinfold thickness in children. Metabolism 1961; 10: 794-807.

14 Clanton TL, Dixon GF, Drake J, Gadek JE. Effects of swim training on lung volumes and inspiratory muscle conditioning. J Appl Physiol 1987; 62: 39-46.

15 Andersen LB, Henckel P, Saltin P. Maximal oxygen utpake in Danish adolescents 16-19 years of age. Eur J Appl Physiol 1987; 56: 74-82

16 Seliger V, Cermak V, Dandzo P et al. Physical fitness of Czechoslovak 12- and 15-year old population. Acta Paediatr Scand 1971; 217 (Suppl): 37-41.

17 Astrand, P-O, Rodahl K. Textbook of Work Physiology. New York: McGraw-Hill, 1986: 295-390.

18 Ribeiro JP, Cavidad E, Baena J et al. Metabolic predictors of middle-distance swimming performance. $\mathrm{Br} J$ Sports Med 1990; 24: 196-200. 